\title{
FDA Terminology
}

National Cancer Institute

\section{Source}

National Cancer Institute. FDA Terminology. NCI Thesaurus. Code C131123.

Terminology subsets associated with the Food and Drug Administration. 